\title{
The Effects of the Paris Agreement on Stock Markets: Evidence from Clean Energy Stocks
}

\author{
Jianing Kuang ${ }^{1 *}$, Ruochen $\mathrm{Zhou}^{2+}$, Diandian $\mathrm{Shi}^{3+}$, Zhengyang $\mathrm{Cai}^{4}$ \\ ${ }^{1}$ Faculty of Arts and Sciences, University of Toronto, Toronto, M5S 3G3, Canada \\ ${ }^{2}$ Jinan New Channel-Jutes High School, Jinan Shandong, 250000, China \\ ${ }^{3}$ Guanghua Qidi Education, Shanghai, 200433, China \\ ${ }^{4}$ Rong Qiao Sedburgh school, Changle Fujian, 350207, China \\ *Corresponding author. Email: jianing.kuang@mail.utoronto.ca \\ + These authors contributed equally to this work and should be considered co-second authors
}

\begin{abstract}
The threats presented by climate change have led to an increasing number of international environmental treaties. In this paper, the effects of the 2016 Paris Agreement on investment behaviors are specifically investigated. By applying the event study methodology, a market model based on S\&P Broad Market Index is used to compute cumulative abnormal returns (CAR) of S\&P Global Clean Energy Index. Overall, the treaty had limited effects on green companies: though a temporary positive effect was shown after the announcement, the implementation appeared to have a statistically negative impact. Furthermore, a linear regression test run between the market capitalization of 6 representative companies and their individual CARs suggest that the differential effect depends both on the scale and the locations of the companies. This work aims to evaluate the effectiveness of climate change treaties and sheds light on potential improvements for further research.
\end{abstract}

Keywords: Climate Change, Paris Agreement, Stock Market, Green Indices, Event Study

\section{INTRODUCTION}

One of the biggest challenges facing humanity in the $21^{\text {st }}$ century is climate change. On July 28th, 2021, "more than 14,000 scientists signed on to an initiative declaring a worldwide climate emergency" because the Earth's vital signs are rapidly worsening [1]. To counter this existential threat, world leaders have gathered to discuss and seek a solution. The fruit of such cooperation was the Paris Agreement. Signed by 197 countries, the Paris Agreement (PA) surpasses the 192 parties of the Kyoto Protocol, marking an important step in humanity's fight against climate change $[2,3]$.

This paper uses the event study analysis methodology to investigate investors' reactions to the Paris Agreement. Event studies are a popular methodology in the world of finance and economics. In this work, the market is represented by the S\&P Global Broad Market Index (BMI), and the clean energy stocks are represented by the S\&P Global Clean Energy Index. The S\&P Global Clean Energy index is comprehensive and comprises clean energy firms of different industries, sizes, and countries.
Thus, its reaction should be an appropriate representation of the global clean energy firms.

The central purpose of this paper is to investigate whether if global climate change negotiations such as the Paris Agreement have a statistically significant positive impact on the stock prices of clean energy firms. Moreover, to what extent does each specific sub-events of the Paris Agreement affect the stock prices of clean energy firms. This paper also seeks to explore and determine the role financial markets play in promoting clean energy and therefore mitigate climate change, and if there are possible areas of improvements to be made.

The paper is structured as follows. Section 2 reviews relevant literature and sets the background. Section 3 describes the selected events and data and the methods used. Section 4 discusses the results and presents our conclusion. Section 5 presents our investigation regarding the relationship between a company's market capitalization. Section 6 is our conclusion and discussion. 


\section{LITERATURE REVIEW}

The Paris Agreement, adopted at the Paris Climate Conference (COP21) in 2015, is the first-ever legally binding global agreement and a key milestone in humanity's efforts to tackle climate change. Estimating the impacts of such climate change agreements on the financial market is an increasingly relevant topic, as the financial market plays a vital role in addressing climate change [4]. In fact, various studies have been done on the stock market's reaction to announcements of climate change agreements, policies, green indices, etc. However, existing event studies have an overwhelming focus on the United States and overlook developing nations that are still increasing their emissions [5]. Thus far, only Schütze et al. (2020) [6] Mukanjari and Sterner (2018) [7] investigated the effect of climate policy events such as the US withdrawal from the Paris Agreement on an international scale.

Climate change agreements and policies have been shown to positively affect environmentally friendly firms. Franziska Schütze et al. (2020) [6] concluded that international climate negotiations have a signaling effect on global financial markets. Likewise, Antoniuk\& Leirvik (2021) [8] corroborates the claim by demonstrating events that raise public awareness of climate change such as the Paris Agreement and Fukushima are favorable for the clean energy sector while those undermining environmental protection policies result in positive abnormal returns for the fossil fuel sector. Juan M. Murguia \& Sergio H. Lence (2015) [9] investigated the market reactions to the release of Newsweek's "Global 100 Green Ranking” and showed that the relative price of the stock has a positive correlation with the ranking of the firm. Moreover, Shreekant Gupta and Bishwanath Goldar (2004) [10] focused on industries in India and found that the environmental performance of a firm directly related to its abnormal return - particularly relevant to developing countries where environmental regulations are weaker.
In contrast, evidence demonstrating negative or mixed effects of climate change policies and agreements on environmentally friendly firms also exist. According to Keele and Dehart (2011) [11] who investigated the impact of an announcement of a partnership with the United States Environmental Protection Agency (USEPA) Climate Leaders program on the stock performance of related firms, cumulative abnormal returns of the stock prices appeared to have statistically significant negative returns for two-thirds of the event windows, manifesting the effect was not positive. Furthermore, the companies listed on the Australian Stock Exchange during 20052011 had similar reactions towards announcements of environmental regulations, as a 31 percentage of reduction for the alternative energy sector in cumulative abnormal returns was recorded due to a carbon-pollution reduction scheme (CPRS) announcement, though mixedeffects could vary by sectors [12].

This paper complements existing literature by expanding the scope of research to include a comprehensive list of clean energy firms from both developed and developing nations. By doing this, the research highlights the global nature of the climate change crisis and consequently the need for a global solution.

\section{DATA AND METHODOLOGY:}

This section defines the four events and the data used to perform the analysis. The event study methodology is also explained in this section.

\subsection{Events}

The Paris Agreement consists of various events spanning over years. Here in the Table 1, this work has selected the most relevant events and their expected effect on clean energy stocks.

Table 1. Different events of the Paris Agreement including their dates and expected effect.

\begin{tabular}{|l|l|l|}
\hline Event & Date & Expected effect on clean energy stocks \\
\hline Adoption of the PA & 2015-Nov-12 & Positive \\
\hline Signing Ceremony of the PA & 2016-Apr-22 & No effect \\
\hline The PA entering into effect & 2016-Nov-4 & Positive \\
\hline $\begin{array}{l}\text { Announcement of the U.S. } \\
\text { withdrawal }\end{array}$ & 2017-June-1 & Negative \\
\hline
\end{tabular}

\subsection{Data}

To calculate the abnormal returns of the clean energy firms during the event windows, two sets of S\&P indices are obtained. The clean energy firms are represented by the S\&P Global Clean Energy Index and the market is represented by the S\&P Global BMI. The constituents of the S\&P Global Clean Energy Index must be members of the S\&P Global BMI and involved in clean energy related technology and equipment. 


\subsection{Event study}

The event study methodology is aimed at measuring the impact of external events on stock performances by obtaining abnormal returns of the stock. It is based on an estimation window, in which the normal return is speculated by calculating the riskiness (slope) and the idiosyncratic returns (intersection) of the market model, alongside an event study window. In this case, an estimation window of 365 days in 2014 (259 trading days) is selected, while the individual event window begins one trading day in advance of the incident in order to include possible fluctuations in stock performances as a result of insider trading and ends 20 trading days afterward, as the impacts are expected to be persistent. Also noteworthy is the fact that this study especially chose the year 2016 (259 trading days) as the second estimation window for the sub-section of the U.S. withdrawal in 2017, since applying the 2014 market model would be inaccurate and biased due to time lag.

As research has manifested, the market model used to predict normal returns establishes a linear correlation between the contemporaneous market returns and the individual stock market returns [13]. It is shown that:

$$
E\left[R_{t}\right]=\alpha+\beta R_{m t}+\varepsilon_{t}, \operatorname{var}\left(\varepsilon_{t}\right)=\sigma^{2}
$$

where $E[R(t)]$ denotes the expected daily return of the stock (S\&P Global Clean Energy Index) and R(mt) represents the return of the market (S\&P Global BMI). Subsequently, abnormal returns can be computed through the following formula:

$$
A R_{t}=R_{t}-\left(\alpha+\beta R_{m t}\right),
$$

where $R(t)$ denotes the authentic stock returns of the stock. Furthermore, the cumulative abnormal returns during the event window can hence be found:

$$
\operatorname{CAR}(\mathrm{t})=\sum_{s=1}^{t} A R_{s}=\sum_{s=1}^{t} \varepsilon_{s} \sim N(0, t \sigma 2) .
$$

The null hypothesis, H0, is the Paris Agreement does not have a statistically significant impact on the stock performance of the S\&P Global Clean Energy Index. Under this hypothesis, the standardized abnormal returns follow normal distribution $\mathrm{AR} \sim \mathrm{N}\left(0, \sigma^{\wedge} 2\right)$, and cumulative abnormal return is likewise normally distributed: $C A R \sim N\left(0, t \sigma^{\wedge} 2\right)$. To test the significance of the effect, a two-tailed t-test with a $95 \%$ confidence interval is applied.

\section{EMPIRICAL RESULTS}

This section reports the findings on the Paris Agreement's effect on clean energy stocks.

\subsection{Market reactions to the Paris Agreement}

The overall result of the research is Paris Agreement (PA) had mixed effects on the stock price of green companies, which means that both positive and negative impacts were brought by PA as time varies.

The results are determined by graphs that show the cumulative abnormal return (CAR) during the event windows and the confidence interval calculated during the estimation window. All the graphs were drawn by Python and below are the graphs:

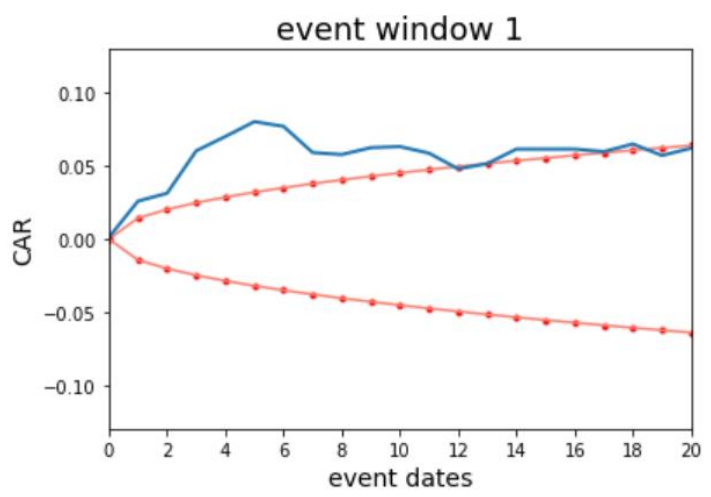

Figure 1 (Adoption of the PA, Nov/11/2015 Jan/8/2016)

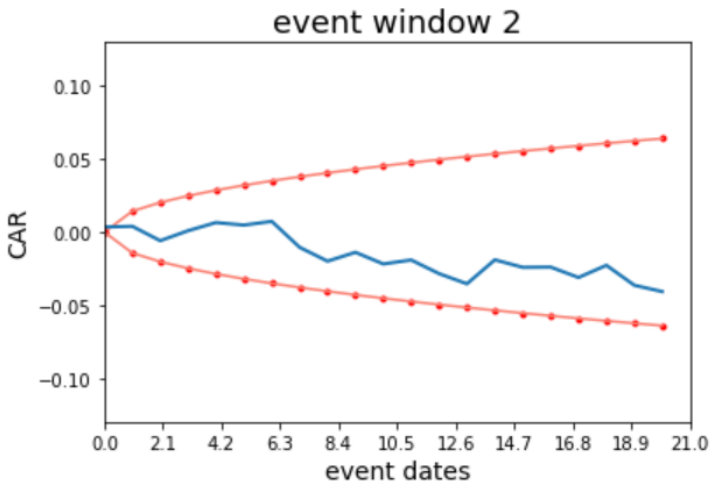

Figure 2 (Signing Ceremony Apr/21/2016 May/19/2016)

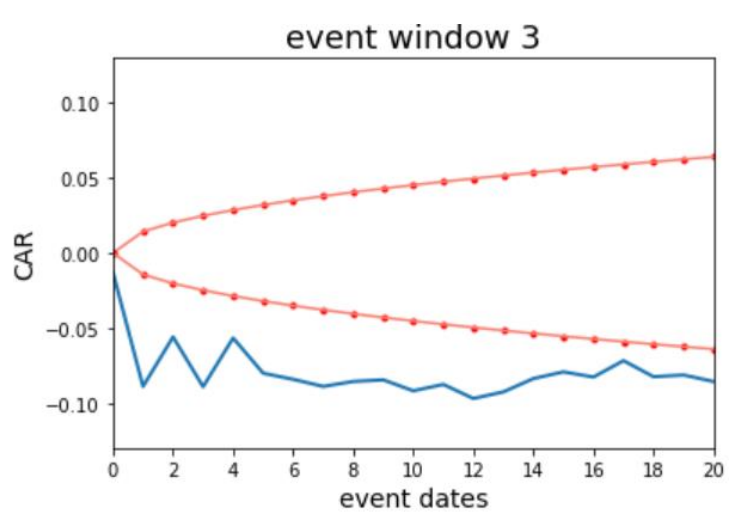

Figure 3 (PA entering into force Nov/3/2016 Dec/1/2016) 


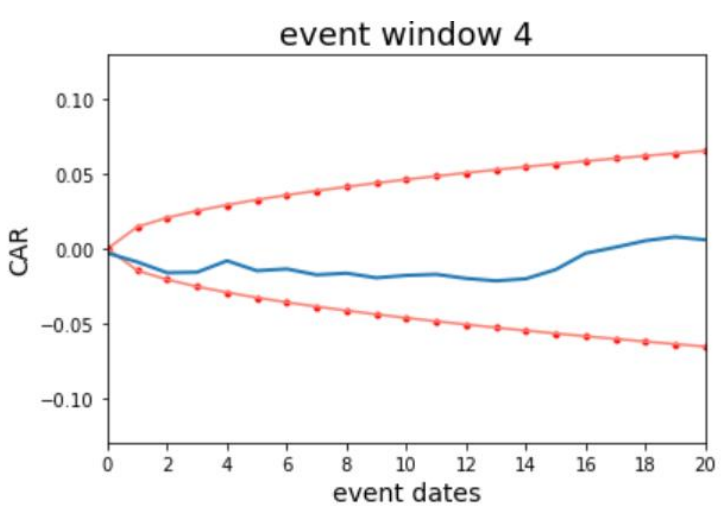

Figure 4 (US withdrawal from the PA May/31/2017 June/28/2017)

Figure 1 to 4 show the impact brought on green stock market by different events of PA in different time.

The most striking and important result to emerge from the data is that the implementation of PA had a huge negative impact on the stock price of green companies worldwide. As shown in Figure 3, the blue line which shows the CAR of the day of putting it into effect and 20 days after it, is always far below the confidence interval, which is the red curve. The lowest point is reached at about 12 days after the event took place, that is, November 11st 2016, at about -0.0926 of CAR. Therefore, there was a significant negative correlation between the implementation of PA and the stock price of the S\&P global clean energy index. At the beginning of this period, the value of CAR fluctuated greatly. By comparison, in the later stage, it gradually became stable at about -0.075 .

Turning now to the statistical evidence in figure 1 which shows the data when the PA is firstly drafted and adopted. The first 12 days after the draft shows a positive significant difference of the CAR and the confidence interval and it reached the peak at the $6^{\text {th }}$ day during the window, at about 0.075 . After the first 12 days, the line of CAR had the tendency to get closer to the confidence interval, while it was still a bit above. Only one point during this window was within the interval, which is November $30^{\text {th }}, 2016$, the $18^{\text {th }}$ day of the period.
Comparing the rest two results with the two analyzed above, the impacts of the signing ceremony and the US withdrawal shown in figure 2 and 4 respectively, were completely not statistically significant. In other words, there was no influence brought by those two events on the stock price of green companies worldwide, since the line of CAR is always within the confidence interval with a stable developing trend. Even there was a tendency of event window 2 to break the interval, the distance was still far.

\subsection{Efficient market hypothesis}

According to the efficient market hypothesis which said that the stock price is always fully reflected by available information, the stock market of green companies can be defined as a semi-strong, or maybe even a strong form of the efficient market hypothesis since not only past prices of the stock, but also public information is reflected in the changes of stock price. However, there is insufficient evidence to support it as a strong form efficient market, since private information is not available to analyze, a firm conclusion on whether private information has had any impact on the stock price during the event window cannot be reached.

\section{DIFFERENTIAL IMPACTS ON COMPANIES:}

Additionally, to further comprehend the impact of the Paris Agreement announcement on companies of different scales, a linear regression test was conducted between the market capitalization of several representative firms included in the S\&P Global Clean Energy Index (31 firms back in 2015 when the event was announced) and their cumulative abnormal returns in the first event window.

\subsection{Methodology}

To start with, 6 distinct constituents shown in Table 2 are selected from the index as the sample.

Table 2. The ranking of 6 selected firms based on market capitalization

\begin{tabular}{|l|l|l|}
\hline $\begin{array}{l}\text { Rank based on market } \\
\text { capitalization }\end{array}$ & Largest firms & Smallest firms \\
\hline 1 & Vestas Wind Systems A/S (Denmark) & $\begin{array}{l}\text { China Shuifa Singyes Energy } \\
\text { Holdings Ltd (China) }\end{array}$ \\
\hline 2 & Enel Green Power SpA (Italy) & REC Silicon ASA (Norway) \\
\hline 3 & Verbund AG (Austria) & JinkoSolar Holding Co Ltd (U.S.) \\
\hline
\end{tabular}

The same method of computing cumulative abnormal returns using market model is then applied to obtain their individual stock performance in the first event window. Furthermore, a scatter graph depicting the relationship this linear regression is illustrated with the $\mathrm{x}$-axis representing the rank of market capitalization $(1=$ the largest firm and $6=$ the smallest firm), since the variation of the actual market value is considerable and might complicate the model. Y-axis shows the final cumulative 
abnormal return of each firm respectively 20 days after the announcement.

\subsection{Empirical Results and Explanations:}

The result is shown below in the Table 3 and Figure

Table 3. the CAR of each company, ranked by market capitalization

\begin{tabular}{|l|l|l|}
\hline Company & $\begin{array}{l}\text { Rank in terms of } \\
\text { market } \\
\text { capitalisation }\end{array}$ & CAR (\%) \\
\hline $\begin{array}{l}\text { Vestas Wind } \\
\text { Systems A/S } \\
\text { (Denmark) }\end{array}$ & 1 & 9.3262 \\
\hline $\begin{array}{l}\text { Enel Green Power } \\
\text { SpA (Italy) }\end{array}$ & 2 & 6.5120 \\
\hline $\begin{array}{l}\text { Verbund AG } \\
\text { (Austria) }\end{array}$ & 3 & -2.6785 \\
\hline $\begin{array}{l}\text { JinkoSolar Holding } \\
\text { Co Ltd (U.S.) }\end{array}$ & 4 & 2.9982 \\
\hline $\begin{array}{l}\text { REC Silicon ASA } \\
\text { (Norway) }\end{array}$ & 5 & -2.8996 \\
\hline $\begin{array}{l}\text { China Shuifa } \\
\text { Singyes Energy } \\
\text { Holdings Ltd } \\
\text { (China) }\end{array}$ & 6 & -5.5279 \\
\hline
\end{tabular}

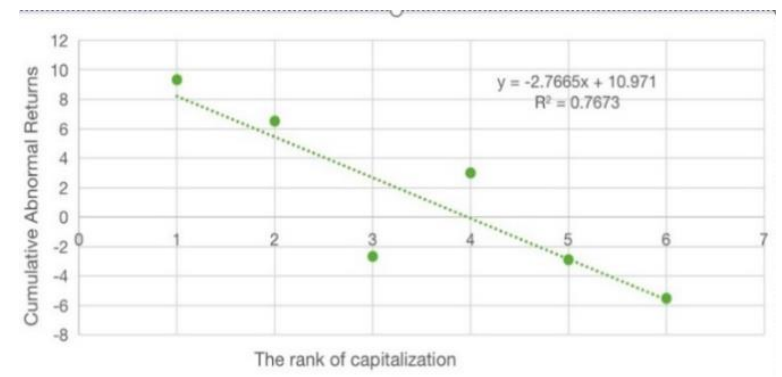

Figure 5 Linear Regression of rank of capitalization against CAR

However, the unexpectedly significant correlation between two variables shown in the Figure 5 indicates that this result requires investigation in depth. Apparently, the methodology is flawed and introduces biases into the outcome: the number of firms (6) could be too limited to be generalized to the whole clean energy market, and several non-negligible variables should have been better controlled. For instance, as the individual effects of international events at a micro-level vary by nations and firms, the location of constituents and alternations in management presumably will influence the result as well.

Among the possible determinants for the result, location is particularly notable. The three largest firms (Italy, Austria, and Denmark) are all members of the
European Union whereas the three smallest firms (China, U.S, and Norway) are coincidentally not. This finding further infers a possible connection between the robustness of climate change policies and how investors react. The European Union has a comprehensive emission trading system in place prior to the Paris Agreement, possibly reducing investor uncertainty and increasing faith. On the contrary, China and the U.S did not have similar national policies in place during the Paris Agreement. Moreover, previous studies conducted by the European Investment Bank indicate EU investors reacted more positively to climate change policies than that of the US [14]. However, Norway is an outlier because even though it joined the EU ETS prior to the Paris Agreement and actively participates in promoting renewable energy, it still experienced negative cumulative abnormal returns. Still, as mentioned in the previous paragraph, sample size limitations and uncontrolled variables prohibit us from reaching a valid conclusion. Further research could be conducted to investigate this relationship more in-depth.

\section{CONCLUSION}

This study investigated the effects of one of the single most notable climate agreements, the Paris Agreement, on clean energy stocks around the world. The data gathered from S\&P global clean energy index and S\&P broad market index (BMI) were analyzed after establishing 4 event windows in chronological order from the drafting/adoption of the Paris Agreement to its signing ceremony, and when it finally entered into force. The last event window is a sub-section that analyses the effect of former US President Donald Trump's withdrawal from the Paris Agreement.

The results have shown that the responses of the financial market varied throughout the various stages of the Paris Agreement. The adoption of the Paris Agreement elicited a positive reaction to clean energy stocks whereas the entering into force negatively impacted the clean energy stocks. However, the signing ceremony and former US president Trump's withdrawal from the Paris Agreement do not affect the stock prices on S\&P global clean energy index.

This work also extended the study to analyze the effect of Paris Agreement on the stock prices of firms with differing market capitalizations, the regression model established discovered that for big companies, the effect was significantly positive, whereas the negative effect was found in small firms.

Here the results from this study are compared to the existing literature that is made by previous authors. These results go in line with the previous reports in which international negotiations have a positive correlation to the stock prices of green firms. Previous studies conducted by Murguia, J. M., \& Lence, S. H. [9] 
corroborate the conclusion. However, there is also research contrary to our findings. Keele and Dehart [11] concluded the market reacts negatively to the announcement of a firm's participation in the USEPA Climate Leaders' program. The results of this study are generally consistent with the results of previous studies.

This study has several strengths and limitations. One strength is in the design of the study itself; the use of global indices allows this study to thoroughly evaluate the impact of the Paris Agreement which is an international agreement. The utilization of global indices also has its negatives - it lacks details. For example, using specific companies would give insights into how differences in management can affect how its stocks are affected - potentially useful for other firms. Another strength is in the number of event windows chosen. The selection of four event windows in chronological order dissects Paris Agreement into its various stages, enabling this study to closely investigate the impact of each. As the results demonstrated, there was considerable variation in the impact of each event, manifesting the Paris Agreement and its effects on the market are much more sophisticated than expected. Another limitation is in the absence of robustness tests. Without performing a robustness test, such as switching the selected indices with other relevant indices, the results may not be rigorous.

Looking into areas of further research, one important direction is on international climate negotiations is to put more emphasis on clean energy firms from emerging markets. Such as, to evaluate how differences exist within in emerging markets like India and China. Likewise, more investigation needs to be conducted on what specific policies have the most positive effects. Lastly, more research can be done to inspect why the market react unexpectedly for two of the event windows. After all, many challenges lie ahead for world leaders who not only need to sign an agreement but also to work together and jointly construct and implement effective, efficient, and integrated policies for climate change to be stopped in time. To overcome these challenges and accomplish this ambitious goal, further economic research will be necessary.

\section{ACKNOWLEDGMENTS}

Jianing is responsible for writing the introduction, literature review, and discussion. Jianing also contributes to the writing of data and methodology, empirical results, differential impacts on companies and conclusion. Diandian is responsible for writing the abstract, data and methodology, and contributes to the differential impacts on companies. Ruochen is responsible for writing the empirical results and contributes to the data and methodology. Zhengyang is responsible for writing the conclusion and contributes to the discussion. All group members closely participated in the making of this essay, truly making it a group project.

\section{REFERENCES}

[1] Thousands of scientists warn climate tipping points 'imminent'. Aljazeera.com. (2021). Retrieved 4 September 2021, from https://www.aljazeera.com/news/2021/7/28/thousa nds-of-scientists-declare-worldwide-climateemergency.

[2] Paris Agreement - Status of Ratification. Unfccc.int. (2021). Retrieved 4 September 2021, from https://unfccc.int/process/the-parisagreement/status-of-ratification.

[3] The Kyoto Protocol - Status of Ratification. Unfccc.int. (2021). Retrieved 4 September 2021, from https://unfccc.int/process/the-kyotoprotocol/status-of-ratification.

[4] Mills, \& Paul. (2008). The greening of markets. Finance \& Development, 45(1), 32-36.

[5] Endrikat, J. (2016). Market reactions to corporate environmental performance related events: a metaanalytic consolidation of the empirical evidence. Journal of Business Ethics, 138(3), 535-548.

[6] Schuetze, F., Aleksovski, D., \& Mozetic, I.. Stock market reactions to international climate negotiations. Social Science Electronic Publishing.

[7] Mukanjari, S., \& Sterner, T. (2018). Do Markets Trump Politics? Evidence from Fossil Market Reactions to the Paris Agreement and the U.S. Election. Retrieved 20 August 2021, from http://hdl.handle.net/2077/55957

[8] Y Antoniuk, \& Leirvik, T. . (2021). Climate change events and stock market returns. Journal of Sustainable Finance \& Investment (1), 1-26.

[9] Murguia, J. M., \& Lence, S. H. (2015). Investors' reaction to environmental performance: a global perspective of the news week's "green rankings". Environmental \& Resource Economics.

[10] Gupta, S., \& Goldar, B. (2005). Do stock markets penalize environment-unfriendly behaviour? evidence from india. Ecological Economics, 52(1), p.81-95.

[11] Keele, D. M., \& Dehart, S. (2011). Partners of USEPA climate leaders: an event study on stock performance. Business Strategy \& the Environment, 20(8), 485-497.

[12] Ramiah, V., Martin, B., \& Moosa, I. (2013). How does the stock market react to the announcement of 
green policies? Journal of Banking \& Finance, 37(5), 1747-1758.

[13] Gabriele, R., Darko, A., Guido, C., Miha, G., Igor, M., \& Tobias, P. (2015). The effects of twitter sentiment on stock price returns. PLoS ONE, 10(9), e0138441.

[14] Bank, I., Bank, A. D., Bank, A. D., Bank, E. I., \& Bank, W. (2011). Joint MDB Report on Mitigation Finance 2011. 